\title{
Palladium-Catalyzed Olefination of Oxazole-Containing Peptides
}

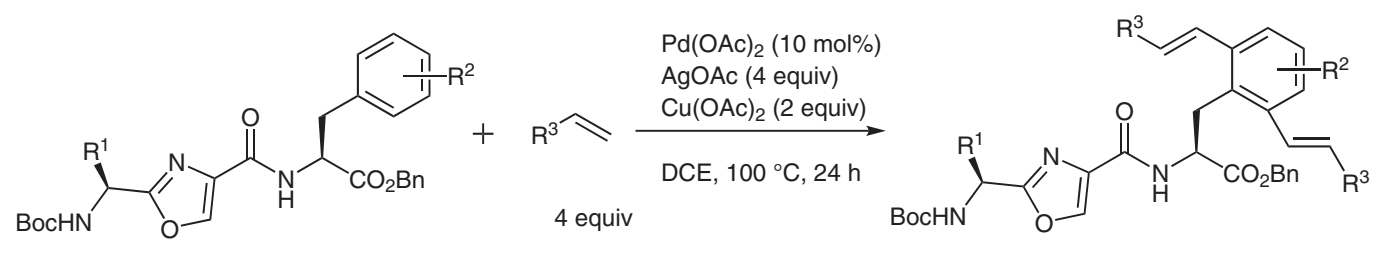

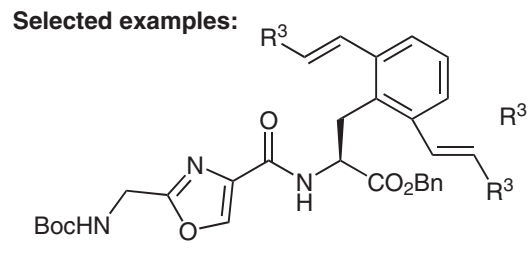<smiles>COc1cc(C=CC(C)(C)C)c(CC(NC(=O)c2coc(CNC(=O)OC(C)(C)C)n2)C(=O)OC(C)(C)C)c(/C=C/C(=O)OCc2ccccc2)c1</smiles><smiles>CCCCOC(=O)COC(=O)CCc1c(/C=C/C(=O)OC(C)(C)C)cccc1/C=C/C(=O)OC(C)(C)C</smiles>
$\mathrm{R}^{1}=\mathrm{Me} \quad 65 \%$ yield $i-\operatorname{Pr} 72 \%$ yield i-Bu $57 \%$ yield $^{\mathrm{a}}$ Bn $62 \%$ yield<smiles>CC(C)(C)OC(=O)NCc1nc(C(=O)NC(Cc2c(C=CC(=O)OCC(NC(=O)OC(C)(C)C)C(=O)OCc3ccccc3)cccc2C=CC(=O)OCC(NC(=O)OC(C)(C)C)C(C)(C)C)C(=O)OCc2ccccc2)co1</smiles>

Macrocyclization:<smiles>C=CC(=O)OCC(NC(=O)OCc1ccccc1)C(=O)N1CCC[C@H]1C(=O)N[C@H](c1nc(C(=O)NC(Cc2ccccc2)C(=O)OCc2ccccc2)co1)C(C)C</smiles>

$\mathrm{Pd}(\mathrm{OAc})_{2}(20 \mathrm{~mol} \%)$ $\mathrm{AgOAc}$ (4 equiv) $\mathrm{Cu}(\mathrm{OAc})_{2}$ (2 equiv)

DCE, $100^{\circ} \mathrm{C}, 24 \mathrm{~h}$

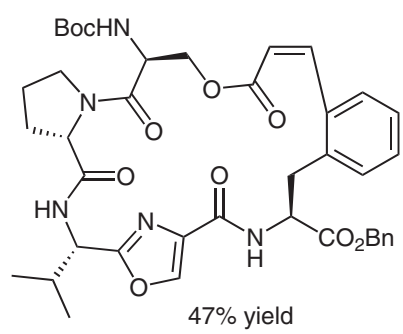

Significance: Late-stage functionalization of peptides has enormous potential for drug discovery. The authors have developed a palladium-catalyzed $\mathrm{C}\left(\mathrm{sp}^{2}\right)-\mathrm{H}$ olefination at the aromatic ring of oxazole-containing peptides.
Comment: The palladium-catalyzed olefination proceeds for various oxazolone-containing peptides. Moreover, this method can be applied to macrocyclization. 